\title{
Prevalence of respiratory and atopic disorders among children in the East and West of Germany five years after unification
}

\author{
S.K. Weiland*, E. von Mutius**, T. Hirsch ${ }^{+}$, H. Duhme*, C. Fritzsch ${ }^{++}$, B. Werner*, A. Hüsing*, \\ M. Stender*, H. Renz ${ }^{\S}$, W. Leupold ${ }^{+}$, U. Keil*
}

\begin{abstract}
Prevalence of respiratory and atopic disorders among children in the East and West of Germany five years after unification. S.K. Weiland, E. von Mutius, T. Hirsch, H. Duhme, C. Fritzsch, B. Werner, A. Hüsing, M. Stender, H. Renz, W. Leupold, U. Keil. C ERS Journals Ltd 1999.

ABSTRACT: Living conditions in eastern Germany have changed rapidly since unification in 1990 and little is known about how these changes affect the prevalence of atopic diseases. This study describes methods and prevalences of a large epidemiological project investigating determinants of childhood asthma and allergies in eastern (Dresden and Leipzig) and western (Munich) Germany in 1995/1996.

Community based random samples of 9-11 yr old children in Dresden $(n=3,017)$ and Munich $(n=2,612)$, and of 5-7 yr old children in Dresden $(n=3,300)$, Leipzig $(n=3,167)$ and Munich $(n=2,165)$ were studied by parental questionnaires, bronchial challenges with hypertonic saline, skin examination, skin-prick tests, and measurements of specific and total serum immunoglobulin (Ig)E using Phase II modules of the International Study of Asthma and Allergies in Childhood (ISAAC).

In 9-11 yr old children, the prevalence of physician diagnosed asthma (7.9\% versus $10.3 \% ; p<0.01)$ and bronchial hyperresponsiveness $(15.7 \%$ versus $19.9 \% ; p<0.05)$ was lower in Dresden than in Munich. No difference between Munich and Dresden was observed in the prevalence of diagnosed hay fever, skin test reactivity to $\geq 1$ allergen, and increased levels $\left(>0.35 \mathrm{kU} \cdot \mathrm{L}^{-\mathrm{P}}\right)$ of specific IgE against inhalant and food allergens. Symptoms and visible signs of atopic eczema tended to be more prevalent in Dresden. Similar East-West differences between the three study areas were seen in the younger age group.

These findings are in line with recently observed increases in the prevalence of hay fever and atopic sensitization, but not of asthma and bronchial hyperresponsiveness, among 9-11 yr old children in Leipzig.

Eur Respir J 1999; 14: 862-870.
\end{abstract}

\begin{abstract}
*Institute of Epidemiology and Social Medicine, University of Münster, Germany, **University Children's Hospital Munich, Germany, ${ }^{+}$Children's Clinic, Technical University Dresden, Germany, ${ }^{++}$University Children's Hospital Leipzig, Germany, Institute of Clinical Chemistry and Biochemistry, University of Berlin, Germany.
\end{abstract}

Correspondence: S.K. Weiland, Institute of Epidemiology and Social Medicine, University of Münster, Domagkstr.3, 48129 Münster, Germany, Fax: 49 2518355300

Keywords: Air pollution

allergies

asthma

epidemiology

ISAAC

respiratory disorders

Received: January 121999

Accepted after revision June 201999

This study was funded by the German Ministry of Education and Research.
The fall of the communist system in many countries in central and eastern Europe provided new opportunities for epidemiological research into the causes of respiratory and atopic diseases [1-12]. The studies comparing eastern and western Germany shortly after German unification in 1990 reported lower prevalence rates of asthma, hay fever, and atopic sensitization both among children and adults in the East as compared to the West of Germany [1-4, 8]. The potential causes of these differences have been associated with "western" living conditions. Specific factors proposed to play a role include indoor exposure to allergens and air pollutants $[5,6,8,9]$, family size $[8,13]$, diet [14], and outdoor air pollution from motor vehicle exhaust fumes $[9,15]$. Studies among adults suggest that factors which were introduced in western Germany during the 1960s and 1970s may be particularly important $[10,12,15]$. Recently, these authors observed an increase in the prevalence of hay fever and atopic sensitization between 1991/92 and 1995/96 among 9-11 yr old children in Leipzig, East Germany [14]. In turn, the prevalence of asthma and bronchial hyperresponsiveness (BHR) to cold air did not change during this period.

The International Study of Asthma and Allergies in Childhood (ISAAC) was initiated to gain new insights into the aetiology of asthma and allergic disorders in children through standardized comparisons of diverse child populations worldwide [16]. Phase I of ISAAC has assessed the prevalence of symptoms of asthma, allergic rhinoconjunctivitis and atopic eczema in 13-14 yr olds in 155 centres around the world by standardized questionnaires and has demonstrated $>20$-fold differences in prevalences between centres [17]. Phase II of ISAAC aims to assess the prevalence of objective markers of atopic diseases and to investigate determinants of atopic conditions in informative populations. A detailed study protocol with several study modules has been developed for use in 9-11 yr old children [18].

In the present paper, the authors report findings of the first cross-sectional studies which were conducted according to the ISAAC Phase II protocol. The studies were part of a large epidemiological project investigating determinants of the East-West differences in prevalence of asthma and allergies in Germany.

\section{Methods}

Study area and populations

The studies were conducted in three cities: Dresden (480,000 inhabitants) and Leipzig $(535,000)$ are located in 
the state of Saxony in the South of former East Germany. Munich (1.3 million) is located in Bavaria in the South of former West Germany. In each city community based random samples of children were studied using schools as sampling units. The older age group comprised all pupils attending fourth grade classes at sampled schools. These children were examined according to the ISAAC Phase II protocol in Dresden and Munich [18]. The authors also analysed blood samples of children of the same age group from Leipzig who had been studied between September 1995 and May 1996 using different questionnaires and other measurements of atopic sensitization and lung function as part of a repeated survey to assess time trends [14]. In addition, community based random samples of children participating in school entry examinations in Munich, Dresden and Leipzig were studied. Because most $(>95 \%)$ fourth grade pupils were aged 9-11 yrs, and most $(>95 \%$ ) school beginners were aged 5-7 yrs at the time of investigation, in the following text 9-11 and 5-7 yr old children will be referred to, in the following text.

\section{Questionnaires}

Following questions on demographic characteristics the parents were asked about respiratory and atopic disorders in their child. The questions included the ISAAC core questions on symptoms of asthma, allergic rhinitis and atopic eczema which have been reported elsewhere [16-19]. Parents were also asked: "Did a doctor ever diagnose any of the following diseases in your child? a) asthma; b) asthmatic, spastic or obstructive bronchitis; c) bronchitis?". Children were defined as having asthma if their parents reported that a doctor had diagnosed "asthma" at least once or "asthmatic, spastic or obstructive bronchitis" more than once. These children were furthermore categorized as having current asthma if the parents had also reported wheeze in the past 12 months. Children were classified as having "bronchitis" if a doctor had diagnosed "bronchitis" more than once and the definition criteria for asthma were not met. Other questions inquired: "Has your child had dry cough at night when she/he did not have a cold in the last 12 months?", "Did your child frequently cough in the morning right after waking up in the last 12 months?", "Has a doctor ever diagnosed hay fever in your child?", "Has a doctor ever diagnosed atopic dermatitis in your child?". In addition, the questionnaires included many detailed questions on different aspects of the child's present and previous living and exposure conditions.

\section{Skin examination}

Participating children were examined for visible flexural dermatitis according to a photographic protocol and detailed instructions on its use in the field $[18,20]$. The examination involved the inspection of the skin, 1) around the eyes, 2) around the sides and front of the neck, 3 ) in front of elbows, 4) behind the knees, and 5) in front of ankles. The presence or absence of signs of visible flexural dermatitis was recorded for each of the five areas.

\section{Skin-prick tests}

Skin-prick tests were performed according to the standardized ISAAC Phase II protocol [18]. The sensitivity to six common aeroallergens was assessed: Dermatopha- goides pteronyssinus, D. farinae, cat, Alternaria tenuis, mixed tree pollen, mixed grass pollen. Standardized allergen extracts and control solutions were provided by ALK (Horsholm, Denmark). A drop of each allergen extract and of the positive (histamine $10 \mathrm{mg} \cdot \mathrm{mL}^{-1}$ ) and negative control (diluent) were brought into the skin of the volar side of the left forearm using ALK lancets. After 15 min the outside contour of the wheal reaction was measured as the mean of the longest diameter and the length of the perpendicular line through its middle. A positive skin reaction was defined as a wheal size $\geq 3 \mathrm{~mm}$ after subtraction of the negative control.

\section{Blood sampling and laboratory analyses}

The parents were also asked for informed consent for a blood sample to be taken from their child. Blood samples were stored in a cooler during the physical examinations in the schools and were prepared in the laboratory later in the day. After centrifugation serum specimens were frozen and stored at $-70^{\circ} \mathrm{C}$ until further analysis.

Levels of specific serum immunoglobulin (Ig)E were measured for all children that gave a serum specimen in one central laboratory (Free University of Berlin, Germany). The concentration of specific IgE against a panel of aeroallergens (mixed grass pollen, birch pollen, mugwort pollen, D. pteronyssinus, cat dander, dog dander, Cladosporium herbarum) was measured by Fluorescence Enzyme Immuno Assay (SX1 CAP; Pharmacia, Lund, Sweden). In addition, the concentration of specific IgE against a panel of food allergens (egg white, milk protein, cod fish, wheat flour, peanut, soybean) was determined by the same method (FX5 CAP; Pharmacia). The latter measurements, however, were performed only in stratified subsamples of children, selected at random from those with and without a positive skin-prick test $(\sim 250$ children per study area, age group and stratum). Finally, levels of total serum $\operatorname{IgE}$ were measured in a $50 \%$ random subsample of all children with serum specimen using the Insulite System (DPC Biermann, Bad Nauheim, Germany).

\section{Spirometry and bronchial challenge}

In 9-11 yr old children lung function was measured by MasterScope Version 4.1 (Jäger, Würzburg, Germany). A minimum of two baseline spirograms was recorded and the highest of two reproducible (within 5\%) measurements of forced expiratory volume in one second (FEV1) was recorded as baseline FEV1 [21]. Bronchial reactivity was assessed by changes in FEV1 after inhalation of nebulized saline using ultrasound nebulizers (DeVilbiss Sunrise Medical, Langen, Germany) [18]. The children inhaled the hyperosmolar $(4.5 \%)$ saline for periods of increasing duration: $0.5,1,2,4$, and $8 \mathrm{~min}$. The FEV1 was measured 1 min after each inhalation period and the next challenge period followed after $3 \mathrm{~min}$. If the FEV1 had fallen by $10-15 \%$ from baseline, the exposure time was repeated. If after two repetitions the FEV1 was still 10-15\% below the baseline value, the duration of the inhalation period was doubled again according to the protocol. In any case, bronchial challenge was stopped either if the FEV1 had fallen at least $15 \%$ from baseline or if the total inhalation period of $15.5 \mathrm{~min}$ had been completed. Saline canister and tubing were weighed before the first and after the last inhalation period to measure the dose of delivered 
aerosol. All children were asked to withhold all asthma medications for at least $12 \mathrm{~h}$. In children $(\mathrm{n}=9)$ with a baseline FEV1 of $<75 \%$ of predicted [22], no bronchial challenge was performed and an inhaled bronchodilator (salbutamol) was administered.

This protocol resulted from minor modifications which became necessary in the beginning of the field work. Initially, the inhalation period was prolonged if children after $15.5 \mathrm{~min}$ had not inhaled at least $23 \mathrm{~mL}$ of saline, the recommended dose for 13-14 yr olds [23]. Since many of the 9-11 yr olds (39 of 98 children tested) did not achieve this dose, the prolongation was stopped after 2 weeks in the field. Between November 7, 1995 and February 8, 1996 the provocation was stopped, if the FEV1 remained between $85-90 \%$ of baseline after only one repetition of an inhalation period (affecting $n=23$ in Munich and $n=22$ in Dresden). To increase the specificity of the bronchial challenge this was changed to the procedure described above. A child was defined as having bronchial hyperresponsiveness (BHR) if, 1) the FEV 1 had dropped by $>15 \%$ from baseline during the inhalation challenge, or 2) (in children tested between November 7, 1995 and February $8,1996)$ if the provocation was stopped because the FEV1 remained at $85-90 \%$ of the baseline value after one repetition of an inhalation period.

Since the hypertonic saline challenge was time consuming it was offered only to random subsamples of the 9-11 yr old children in Dresden $(n=1,999)$ and Munich $(n=$ 2,019 ). Some children with complete lung function measurements could not be challenged because of technical or organizational problems $(n=140$ in Dresden and $n=85$ in Munich). Other children did not complete the bronchial challenge because of health (e.g. cough, nausea) complaints ( $n=42$ and $n=48$ respectively) or limited motivation ( $n=19$ and $n=58$, respectively) giving a participation rate for a complete bronchial challenge of 52\% in Dresden and $56 \%$ in Munich.

\section{Field work and participation}

The parental questionnaires were distributed through the schools in 9-11 yr olds, and through the local authorities organizing the school entry examination in 5-7 yr old children. Parents were asked to fill in the questionnaire and to give informed consent for each study instrument separately. The surveys were announced to parents and teachers as studies on respiratory and skin problems.

In Dresden and Munich, all 9-11 yr old children and random subsamples of 5-7 yr old children were invited to participate in the skin examination, skin-prick testing, and blood sampling. Random subsamples of 9-11 yr olds in Dresden and Munich were also invited to participate in the bronchial challenges. The numbers of children who were invited and who participated in the different study instruments by age group and study area are given in table 1 . In general, the response rate was similar in Munich and Dresden. Differences of $>10 \%$ were observed for blood sampling in 9-11 yr olds and skin examination in 5-7 yr olds. A history of diagnosed atopic disease in the child or parents did not substantially affect the participation within a study area and age group. A few minor but statistically significant $(\mathrm{p}<0.05)$ differences in participation were observed. Among 5-7 year olds in Dresden participation in blood sampling differed depending on whether or not the child had atopic eczema (54\% versus $47 \%$ ). In 9-11 yr olds, participation in skin-prick testing was lower in Dresden when the child had hay fever $(67 \%$ versus $75 \%$ ) or asthma (67\% versus $75 \%$ ) and was higher in Munich when the parents had atopic diseases $(72 \%$ versus $68 \%$ ).

The 9-11 yr old children were examined in the schools during school hours, while 5-7 yr olds were seen following the school entry examination. In Dresden, data were collected on 9-11 yr olds between September 1995 and June 1996, and on 5-7 yr olds between July 1995 and March 1996. The field work on 9-11 yr old children in Munich was conducted between September 1995 and December 1996. The extended data collection period was necessary to ensure bronchial challenges in a sufficient number of children, because in Munich children spent less time at school and the proportion of children with German nationality was lower. The 5-7 yr olds in Munich were investigated between April and July 1996. In Leipzig, children of the younger age group were studied between August 1995 and May 1996, while the 9-11 yr old children were examined between September 1995 and May 1996.

Table 1. - Number of children who were invited $(\mathrm{N})$, children who participated $(\mathrm{n})$, and children with German nationality who were considered in the analysis (S) by instruments, age group and study area, 1995/1996

\begin{tabular}{|c|c|c|c|c|c|c|c|c|c|}
\hline & \multicolumn{3}{|c|}{ Munich } & \multicolumn{3}{|c|}{ Dresden } & \multicolumn{3}{|c|}{ Leipzig } \\
\hline & $\mathrm{n} / \mathrm{N}$ & $\%$ & $\mathrm{~S}$ & $\mathrm{n} / \mathrm{N}$ & $\%$ & $\mathrm{~S}$ & $\mathrm{n} / \mathrm{N}$ & $\%$ & S \\
\hline \multicolumn{10}{|l|}{ 9-11 yr old children } \\
\hline Questionnaire & $3354 / 3830$ & 87.6 & 2612 & $3045 / 3668$ & 83.0 & 3017 & $\mathrm{NC}$ & - & \\
\hline Skin examination & $2512 / 3830$ & 65.6 & 1969 & $2429 / 3668$ & 66.2 & 2408 & $\mathrm{NC}$ & - & \\
\hline Skin-prick tests & $2318 / 3830$ & 60.5 & 1812 & $2260 / 3668$ & 61.6 & 2242 & $\mathrm{NC}$ & - & \\
\hline Serum IgE & $1740 / 3830$ & 45.4 & 1331 & $2083 / 3668$ & 56.8 & 2068 & $1232 / 2666$ & 46.2 & 1222 \\
\hline Lung function & $1333 / 2019^{\#}$ & 66.0 & 1064 & $1256 / 1999^{\#}$ & 62.8 & 1249 & $\mathrm{NC}$ & - & \\
\hline Bronchial responsiveness & $1140 / 2019^{\#}$ & 56.5 & 904 & $1048 / 1999^{\#}$ & 52.4 & 1042 & $\mathrm{NC}$ & - & \\
\hline \multicolumn{10}{|l|}{ 5-7 yr old children } \\
\hline Questionnaire & $2890 / 3679$ & 78.6 & 2165 & $3312 / 3866$ & 85.7 & 3300 & $3217 / 4549$ & 70.7 & 3167 \\
\hline Skin examination & $1138 / 1875^{\#}$ & 60.7 & 797 & $1803 / 2328^{\#}$ & 77.4 & 1796 & NP & & \\
\hline Skin-prick tests & $1104 / 1875^{\#}$ & 58.9 & 765 & $1360 / 2328^{\#}$ & 58.4 & 1355 & NP & - & \\
\hline Serum IgE & $829 / 1875^{\#}$ & 44.2 & 564 & $954 / 2328^{\#}$ & 41.0 & 952 & NP & - & \\
\hline
\end{tabular}

NP: these examinations were not performed in Leipzig. " : random subsample. IgE: immunoglobulin E; NC: due to different study instrument not comparable with Munich and Dresden. 


\section{Quality control}

Field workers examining 9-11 yr old children in Munich and Dresden were trained together for 1 week in all aspects of field work following a detailed study manual. The field workers examining 5-7 yr olds were trained in the two cities separately, but by the same trainer and also according to a detailed study manual. The standardization and quality of field work in both areas received much attention throughout the whole study period. Nebulizers and equipment to measure lung function were checked regularly. All teams were supervised periodically by announced and unannounced site visits of field supervisors. The quality of incoming data was closely monitored by the Coordinating and Data Center in Münster throughout the data collection period. All studies of the multicentre project were approved by the ethics committee of the University of Münster.

\section{Air pollution}

Data on air pollution in the three cities were provided by the Sächsisches Landesaint für Umwelt und Geologie in Dresden and the Bayerisches Landesamt für Umweltschutz in Munich. The methods used to measure concentrations of $\mathrm{SO}_{2}$ (ultraviolet fluorescence), suspended particulate matter ( $\beta$-absorption) and $\mathrm{NO}_{2}$ (chemiluminiescence) are the same in the three cities since 1992. In order to also give information on previous exposure conditions the authors present measurements of $\mathrm{SO}_{2}$ for 1989, 1990 and 1991 in Dresden and Leipzig which were performed using a different technique (coulombmetric method), allow comparison between the two eastern cities.

\section{Statistical analyses}

Data were entered, checked and prepared for analyses in Münster. Since the proportion of children without German nationality, who have been reported to have a lower prevalence of atopic disorders [24], differed greatly between the eastern $(\sim 2 \%)$ and western $(\sim 25 \%)$ study areas the comparison of prevalence rates was restricted to children with German nationality (table 1). Prevalence rates based on questionnaire responses were calculated using those who had responded to the respective questions as denominator. To calculate predicted values, lung function measurements were computed as a linear function of age, height and weight using children without parental report of asthma or wheezing in the last 12 months as reference population. These calculations were performed for both cities combined, but for males and females separately. The derived coefficients were applied to compute predicted lung function values for all children. Chi-squared tests were performed to compare prevalence rates between study areas, while t-tests were used for the comparison of continuous variables between populations. All computations were performed using SAS Software (SAS Institute Inc., Cary, NC, USA).

\section{Results}

The age and sex distributions of participating children in the two age groups and three study areas are shown in table 2. Among the 9-11 yr old children prevalence estimates of symptoms and diagnoses of asthma were lower in Dresden than in Munich, reaching statistical significance for speech limiting wheeze, doctor diagnosed asthma and current asthma (table 3). In turn, bronchitis was reported significantly more often in Dresden as compared to Munich. A similar pattern was seen in the younger age group. In both age groups, symptoms of allergic rhinoconjunctivitis during the last 12 months were reported less frequently in Dresden than in Munich. However, the prevalence of doctor diagnosed hay fever did not differ between the two cities in any age group. Only 5-7 yr old children in Leipzig had a significantly lower prevalence of hay fever than their peers in Munich. Symptoms and visible signs of flexural dermatitis among children of both age groups were more prevalent in Dresden than in Munich.

The results of the lung function measurements show lower values (as per cent of predicted) of forced vital capacity (FVC) for children in Dresden as compared to Munich (table 4). No significant difference occurred between the cities in measurements of FEV1. Values of peak

Table 2. - Demographic characteristics of the study population

\begin{tabular}{|c|c|c|c|c|c|c|}
\hline & \multicolumn{2}{|c|}{ Munich } & \multicolumn{2}{|c|}{ Dresden } & \multicolumn{2}{|c|}{ Leipzig } \\
\hline & $\mathrm{n}^{\#}$ & $\%$ & $\mathrm{n}^{\#}$ & $\%$ & $\mathrm{n}^{\#}$ & $\%$ \\
\hline 9-11 yr old children $(\mathrm{N})$ & \multicolumn{2}{|c|}{2612} & \multicolumn{2}{|c|}{3017} & \multicolumn{2}{|c|}{2311} \\
\hline Age yrs & & & & & & \\
\hline$\leq 9$ & 1373 & 52.6 & 1044 & 34.6 & 698 & 30.2 \\
\hline 10 & 1140 & 43.6 & 1772 & 58.7 & 1412 & 61.1 \\
\hline$\geq 11$ & 63 & 2.4 & 189 & 6.3 & 199 & 8.6 \\
\hline \multicolumn{7}{|l|}{ Sex } \\
\hline Male & 1288 & 49.3 & 1565 & 51.9 & 1180 & 51.1 \\
\hline Female & 1323 & 50.7 & 1451 & 48.1 & 1131 & 48.9 \\
\hline 5-7 yr old children $(\mathrm{N})$ & \multicolumn{2}{|c|}{2165} & \multicolumn{2}{|c|}{3300} & \multicolumn{2}{|c|}{3167} \\
\hline Age yrs & & & & & & \\
\hline$\leq 5$ & 197 & 9.1 & 2188 & 66.3 & 1905 & 60.2 \\
\hline 6 & 1889 & 87.3 & 1093 & 33.1 & 1178 & 37.2 \\
\hline$\geq 7$ & 78 & 3.6 & 2 & 0.1 & 41 & 1.3 \\
\hline \multicolumn{7}{|l|}{ Sex } \\
\hline Male & 1102 & 50.9 & 1724 & 52.2 & 1663 & 52.5 \\
\hline Female & 1063 & 49.1 & 1575 & 47.7 & 1499 & 47.3 \\
\hline
\end{tabular}

\footnotetext{
\#: numbers do not add up due to missing values. N: children with German nationality.
} 
Table 3. - Prevalence of symptoms and diagnoses of respiratory and allergic disorders, and of visible flexural dematitis in children by age group and study area

\begin{tabular}{|c|c|c|c|c|c|c|}
\hline & \multicolumn{2}{|c|}{ Munich } & \multicolumn{2}{|c|}{ Dresden } & \multicolumn{2}{|c|}{ Leipzig } \\
\hline & $\mathrm{n}$ & $\%$ & $\mathrm{n}$ & $\%$ & $\mathrm{n}$ & $\%$ \\
\hline 9-11 yr old children $\mathrm{N}$ & \multirow{2}{*}{\multicolumn{2}{|c|}{$(2612)$}} & \multirow{2}{*}{\multicolumn{2}{|c|}{$(3017)$}} & \multirow{2}{*}{\multicolumn{2}{|c|}{ - }} \\
\hline Symptoms in the last 12 months & & & & & & \\
\hline Wheeze & 221 & 8.6 & 234 & 7.9 & & \\
\hline$\geq 4$ attacks of wheezing & 61 & 2.4 & 49 & 1.7 & & \\
\hline Speech limiting wheeze & 70 & 2.7 & 56 & $1.9^{*}$ & & \\
\hline Waking with cough & 423 & 16.4 & 491 & 16.5 & & \\
\hline Morning cough & 319 & 12.4 & 350 & 11.8 & & \\
\hline Runny nose with itchy eyes & 384 & 15.0 & 372 & $12.6^{*}$ & & \\
\hline Flexural dermatitis & 295 & 11.5 & 479 & $16.1 * * *$ & & \\
\hline \multicolumn{7}{|l|}{ Diagnosis ever ${ }^{\#}$} \\
\hline Asthma & 264 & 10.3 & 235 & $7.9 * *$ & & \\
\hline Current asthma & 132 & 5.1 & 119 & $4.0^{*}$ & & \\
\hline Bronchitis & 575 & 24.4 & 1041 & $36.8^{* * *}$ & & \\
\hline Hay fever & 235 & 9.3 & 289 & 9.8 & & \\
\hline Atopic dermatitis & 441 & 17.5 & 482 & 16.6 & & \\
\hline Visible flexural dermatitis ${ }^{\# \#} \mathrm{~N}$ & \multicolumn{2}{|c|}{1969} & \multicolumn{2}{|c|}{2408} & \multicolumn{2}{|c|}{-} \\
\hline Yes & 94 & 4.8 & 151 & $6.3^{*}$ & & \\
\hline 5-7 yr old children $\mathrm{N}$ & \multicolumn{2}{|c|}{2165} & \multirow{2}{*}{\multicolumn{2}{|c|}{3300}} & \multirow{2}{*}{\multicolumn{2}{|c|}{3167}} \\
\hline Symptoms in the last 12 months & & & & & & \\
\hline Wheeze & 191 & 9.0 & 222 & $6.9 * *$ & 253 & 8.2 \\
\hline$\geq 4$ attacks of wheezing & 47 & 2.2 & 38 & $1.2 * *$ & 38 & $1.2 * *$ \\
\hline Speech limiting wheeze & 41 & 1.9 & 46 & 1.4 & 56 & 1.8 \\
\hline Waking with cough & 435 & 20.4 & 449 & $13.9 * * *$ & 520 & $16.6^{* * *}$ \\
\hline Morning cough & 329 & 15.5 & 321 & $10.0 * * *$ & 380 & $12.2 * * *$ \\
\hline Runny nose with itchy eyes & 161 & 7.6 & 180 & $5.6^{* *}$ & 137 & $4.4 * * *$ \\
\hline Flexural dermatitis & 192 & 9.0 & 378 & $11.8^{* *}$ & 304 & 9.8 \\
\hline \multicolumn{7}{|l|}{ Diagnosis ever ${ }^{\#}$} \\
\hline Asthma & 210 & 10.0 & 184 & $5.8 * * *$ & 231 & $7.5^{* *}$ \\
\hline Current asthma & 101 & 4.7 & 102 & $3.1 * *$ & 100 & $3.2 * *$ \\
\hline Bronchitis & 411 & 21.3 & 974 & $33.0 * * *$ & 907 & $31.8 * * *$ \\
\hline Hay fever & 97 & 4.6 & 139 & 4.3 & 81 & $2.6 * * *$ \\
\hline Atopic dermatitis & 332 & 15.9 & 546 & 17.5 & 405 & $13.5^{*}$ \\
\hline Visible flexural dermatitis $^{\# \#} \mathrm{~N}$ & \multicolumn{2}{|c|}{797} & \multicolumn{2}{|c|}{1796} & & \\
\hline Yes & 50 & 6.3 & 170 & $9.5^{* *}$ & & \\
\hline
\end{tabular}

*: $\mathrm{p}<0.05 ; * *: \mathrm{p}<0.01 ; * * *: \mathrm{p}<0.001$ using Chi-squared tests for the comparison to Munich; ${ }^{\#}:$ assessed by questionnaire; ${ }^{\# \#}:$ assessed by skin examination; N: number of children who were considered in one analyses; $n$ : number of children who's parents responded affirmatively to the respective question.

expiratory flow (PEF) and maximal mid-expiratory flow (MMEF), and the ratio FEV1/FVC were significantly higher in Dresden. In addition, the prevalence of BHR to hypertonic saline was significantly lower in Dresden than in Munich.

No difference between Dresden and Munich was found for the prevalence of skin test reactivity to at least one allergen (table 5). Analyses by allergen showed higher prevalences for sensitivity against tree pollen and, only among 9-11 yr olds, against dust mites and A. tenuis in Dresden than in Munich. The prevalence of increased specific serum IgE levels against inhalant allergens in 5-7 yr olds did not differ between the two cities. Levels of IgE- against areoallergens in 9-11 yr old children tended to be lower in Dresden than in Munich, reaching statistical significance for IgE levels $>0.7 \mathrm{kU} \cdot \mathrm{L}^{-1}$. There was no statistically significant difference in the prevalence of specific IgE against food allergens between the two cities in any of the age groups. In 9-11 yr olds in Leipzig increased serum IgE against inhalant allergens were significantly less prevalent than in Munich and Dresden. Total serum IgE levels, in turn, tended to be higher both in
Dresden and Leipzig than in Munich, the difference between 5-7 yr olds in Dresden and Munich reached statistical significance.

\section{Discussion}

The findings suggest that in 1995/1996 the prevalence of asthma was lower in children in Dresden and Leipzig than in Munich. The questionnaire data are supported by the objective measurements of lung function and bronchial responsiveness in 9-11 yr olds. The difference in the prevalence of BHR between Munich and Dresden was more pronounced in those challenged after February 8, 1996. The modified challenge protocol had a higher specificity and a lower sensitivity in relation to asthma symptoms and diagnoses (data not shown). This is reflected in the lower prevalence estimates of BHR using this protocol. Relatively lower prevalences of asthma among children and adults in eastern Germany have also been found in other investigations $[1-4,8,9]$. The findings are also in line with recent observations among 9-11 yr old children in Leipzig 
Table 4. - Lung function and bronchial hyperresponsiveness (BHR) to hypertonic saline among 9-11 yr old children in Munich and Dresden

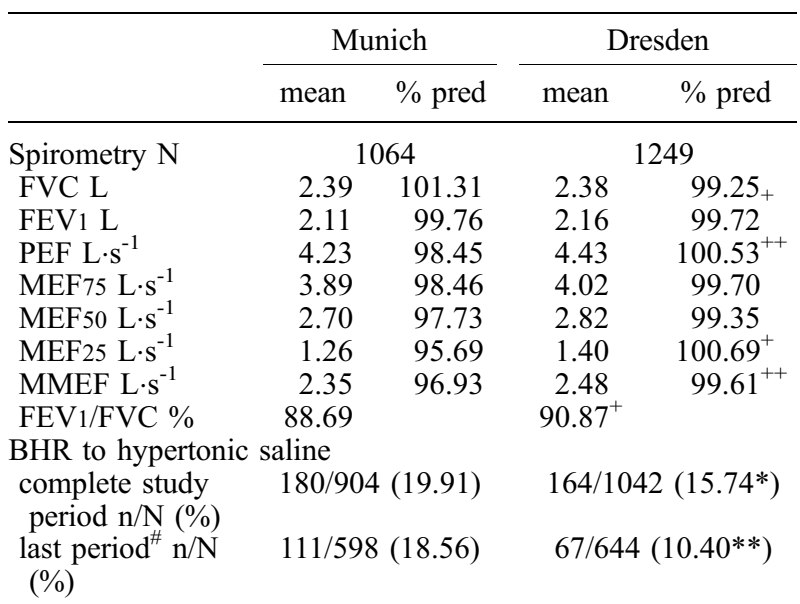

\#: period after February 81996 and modification of challenge protocol; ${ }^{+}: \mathrm{p}<0.001 ;{ }^{++}: \mathrm{p}<0.01$, using t-tests for the comparison with Munich; *: $<<0.05 ; * *: p<0.01$, using Chi-squared tests for the comparisons with Munich. N: number of children who were considered in the analyses; $\mathrm{n}$ : number of children with BHR; FVC: forced vital capacity; FEV1: forced expiratory volume in one second; PEF: peak expiratory flow; MEF75, MEF50, MEF25: mid-expiratory flow when 75,50 and $25 \%$ (respectively) of FVC remains to be exhaled; MMEF: maximum mid-expiratory flow.

[14] showing no increase in the prevalence of asthma and BHR between 1991/1992 and 1995/1996.

Studies conducted shortly after unification found lower prevalence rates of hay fever and atopic sensitization in children and adults living in the East as compared to the West of Germany [3, 4, 8-10, 12]. The current data, collected 5 yrs after unification, show no significant differences in the prevalence of hay fever, skin test reactivity to at least one allergen, and increased $\left(<0.35 \mathrm{kU} \cdot \mathrm{L}^{-1}\right)$ specific $\mathrm{IgE}$ against inhalant or food allergens between Dresden and Munich. This, again, is in keeping with the observed increase in prevalence of hay fever and atopic sensitization, assessed by skin-prick test, among 9-11 yr olds in Leipzig [14]. It is interesting to note that in Leipzig the strongest increase was found for sensitization against tree pollen and mites. The present study shows higher sensitization rates in Dresden for exactly these allergens. Yet, despite the higher sensitization against house dust mites the prevalence of asthma and BHR in 9-11 yr olds was lower in Dresden than in Munich.

Previous comparisons of populations in the East and West of Germany found higher concentrations of total serum IgE among children and adults living in the East [3, 8]. In the present study total serum IgE levels also tended to be higher among children in Dresden and Leipzig than in Munich, reaching statistical significance in the younger age group. Causes for the higher IgE concentrations in eastern Germany are unclear. The number of subjects per dwelling and parasitic infections have been suggested as potential determinants $[3,8]$, but findings of a recent study argue against a role of helminthic infections [25]. While total IgE levels are closely related to atopy in individuals, it has been shown that the prevalences of specific $\operatorname{IgE}$ and levels of total $\operatorname{IgE}$ in populations of adults vary independently of each other, suggesting differences in the influence of environmental factors [26].

It has been an intriguing observation of some earlier investigations on children in Germany that the prevalence of atopic dermatitis was higher in areas in the East than in the West $[2,3,27]$. These studies included skin examinations by dermatologists [27]. The finding of the current study that symptoms and signs of atopic dermatitis were more prevalent in Dresden than in Munich is in line with these observations. The reasons for relatively higher prevalences of atopic dermatitis in the eastern areas, however, remain to be elucidated.

Another interesting result of this study is that the prevalence of specific serum IgE against inhalant allergens among 9-11 yr olds was lower in Leipzig than in Dresden. In addition, symptoms and diagnoses of atopic rhinitis and eczema in 5-7 yr olds tended to be reported less frequently in Leipzig. There is yet no explanation for this difference which will be explored in future investigations. Differences in the prevalence of childhood allergies between centres in eastern Germany, however, have also been reported previously $[2,3]$ and this must be kept in mind when interpreting studies which were conducted in a small number of areas.

The observed differences in the prevalence of respiratory and atopic diseases could not be explained by differences in the age and sex distribution of the study populations. Furthermore, there was little evidence that diagnostic bias has played a role in the observed East-West differences. The prevalence of respiratory symptoms (wheeze, $\geq 4$ attacks of wheezing, speech limiting wheeze, and morning cough), skin test reactivity, increased specific serum IgE levels, and BHR among 9-11 yr old children with a diagnosis of asthma and of bronchitis was very similar in eastern and western Germany. Minor differences which reached statistical significance were seen only in 57 yr olds. For children with diagnosed asthma wheezing during the past year was reported less often in Munich $(48.1 \%)$ than in Dresden $(58.3 \%)$, while for children with bronchitis $\geq 4$ attacks of wheezing and morning cough during the past year were reported more often in Munich $(2.7 \%$ and $30.3 \%)$ than in Dresden $(0.5 \%$ and $20.0 \%)$ and Leipzig (0.9\% and $22.8 \%)$.

Figure 1 gives an overview of the level of air pollution in the three study areas between 1989 and 1996. Drastic reductions in the concentrations of $\mathrm{SO}_{2}$ in ambient air were achieved in Leipzig and Dresden. This was mostly due to reductions in emissions from heavy industry, power plants and private heating. During the 1980 s, the concentrations of $\mathrm{SO}_{2}$ used to be higher in Leipzig than in Dresden caused in part by a higher sulphur content of the coal burned in Leipzig. Differences in levels of suspended particulates (SP) between the three areas and their changes over time are less pronounced. Annual mean concentrations of $\mathrm{NO}_{2}$, in turn, were lower in Dresden and Leipzig than in Munich, but have been increasing in both cities due to increased automobile traffic from 19921996. Despite the substantially higher exposure to $\mathrm{SO}_{2}$ in the eastern study areas, the prevalence of asthma and BHR among children in these cities was lower than in Munich. However, children in Dresden and Leipzig had a higher lifetime prevalence of recurrent bronchitis. This observation is consistent with other reports suggesting 
Table 5. - Prevalence of atopic sensitization and levels of total and specific serum immunoglobulin (Ig)E in children by age group and study area

\begin{tabular}{|c|c|c|c|c|c|c|}
\hline & \multicolumn{2}{|c|}{ Munich } & \multicolumn{2}{|c|}{ Dresden } & \multicolumn{2}{|r|}{ Leipzig } \\
\hline & $\mathrm{n}$ & $\%$ & $\mathrm{n}$ & $\%$ & $\mathrm{n}$ & $\%$ \\
\hline \multicolumn{7}{|l|}{ 9-11 yr old children } \\
\hline Positive skin prick test $\mathrm{t}^{\#} \mathrm{n}$ & \multicolumn{2}{|c|}{1812} & \multicolumn{2}{|c|}{2242} & & \\
\hline D. ptr. & 141 & 7.8 & 224 & $10.0 *$ & & - \\
\hline D. far. & 80 & 4.4 & 162 & $7.2 * * *$ & & - \\
\hline Tree pollen & 77 & 4.2 & 185 & $8.3 * * *$ & & - \\
\hline Grass pollen & 295 & 16.3 & 345 & 15.4 & & - \\
\hline Cat & 155 & 8.6 & 204 & 9.1 & & - \\
\hline A. ten. & 5 & 0.3 & 32 & $1.4^{* * *}$ & & - \\
\hline At least one & 425 & 23.5 & 576 & 25.7 & & - \\
\hline Specific serum IgE n & \multirow{2}{*}{\multicolumn{2}{|c|}{1331}} & \multirow{2}{*}{\multicolumn{2}{|c|}{2068}} & \multirow{2}{*}{\multicolumn{2}{|c|}{1222}} \\
\hline Inhalant allergens & & & & & & \\
\hline $\begin{array}{l}>0.35 \mathrm{kU} \cdot \mathrm{L}^{-1} \\
>0.70 \mathrm{kU} \cdot \mathrm{L}^{-1}\end{array}$ & $\begin{array}{l}534 \\
478\end{array}$ & $\begin{array}{l}40.1 \\
35.9\end{array}$ & $\begin{array}{l}766 \\
656\end{array}$ & $\begin{array}{l}37.1 \\
31.8^{*}\end{array}$ & $\begin{array}{l}353 \\
294\end{array}$ & $\begin{array}{l}28.9 * * * \\
24.1 * * *\end{array}$ \\
\hline \multicolumn{7}{|l|}{ Food allergens } \\
\hline$>0.35 \mathrm{kU} \cdot \mathrm{L}^{-1}$ & - & 20.5 & - & 17.6 & & - \\
\hline$>0.70 \mathrm{kU} \cdot \mathrm{L}^{-1}$ & - & 11.2 & - & 8.9 & & - \\
\hline Total serum IgE n & \multirow{2}{*}{\multicolumn{2}{|c|}{671}} & \multicolumn{2}{|c|}{1036} & \multirow{2}{*}{\multicolumn{2}{|c|}{$\begin{array}{c}680 \\
55.13\end{array}$}} \\
\hline Geometric mean & & 52.48 & \multirow{2}{*}{\multicolumn{2}{|c|}{$\begin{array}{c}57.44 \\
4.05 \pm 0.044\end{array}$}} & & \\
\hline Mean of $\log \operatorname{IgE} \pm$ SEM & \multirow{2}{*}{\multicolumn{2}{|c|}{$3.96 \pm 0.06$}} & & & \multicolumn{2}{|r|}{$4.01 \pm 0.054$} \\
\hline 5-7 yr old children & & & \multicolumn{2}{|c|}{$4.05 \pm 0.044$} & \multicolumn{2}{|r|}{-} \\
\hline Positive skin prick test $\mathrm{n}$ & \multicolumn{2}{|c|}{765} & \multicolumn{2}{|c|}{1355} & \multicolumn{2}{|r|}{-} \\
\hline D. ptr. & 22 & 2.9 & 30 & 2.2 & \multicolumn{2}{|r|}{-} \\
\hline D. far. & 9 & 1.2 & 22 & 1.6 & \multicolumn{2}{|r|}{-} \\
\hline Tree pollen & 12 & 1.6 & 45 & $3.3^{*}$ & \multirow{2}{*}{\multicolumn{2}{|c|}{-}} \\
\hline Grass pollen & 45 & 5.9 & 94 & 6.9 & & \\
\hline Cat & 21 & 2.7 & 45 & 3.3 & & - \\
\hline A. ten. & 0 & 0.0 & 5 & 0.4 & & - \\
\hline At least one & 76 & 9.9 & 163 & 12.0 & & - \\
\hline Specific serum IgE n & & & & & & \\
\hline Inhalant allergens $\mathrm{SX}_{1}$ & & & & & & \\
\hline$>0.35 \mathrm{kU} \cdot \mathrm{L}^{-\mathrm{I}}$ & 151 & 26.8 & 252 & 26.5 & & - \\
\hline$>0.70 \mathrm{kU} \cdot \mathrm{L}^{-1}$ & 128 & 22.7 & 212 & 22.3 & & - \\
\hline Food allergens & & & & & & \\
\hline$>0.35 \mathrm{kU} \cdot \mathrm{L}^{-1}$ & - & 17.8 & - & 21.2 & & - \\
\hline$>0.70 \mathrm{kU} \cdot \mathrm{L}^{-1}$ & - & 9.9 & - & 11.7 & & - \\
\hline Total serum IgE n & & & & & & \\
\hline Geometric mean & & & & & & - \\
\hline Mean of $\log \operatorname{IgE} \pm \mathrm{SEM}$ & & & & $65^{*}$ & & - \\
\hline
\end{tabular}

\#: a positive reaction was defined as a $\geq 3 \mathrm{~mm}$ wheal after subtraction of the reaction to the negative control; ${ }^{\# \#}$ : estimate based analyses of stratified subsamples of children (see text); ${ }^{*}$ : $p<0.05 ; * * *: p<0.001$ using Chi-squared tests for the comparison to Munich; $: p<0.05$ using t-test for the comparison to Munich. N: number of children who were considered in the analyses; n: number of children with a positive test result; D. ptr: Dermatophagoides pteronyssinus; D. far: Dermatophagoides farinae; A. ten.: Alternaria tenuis.

that long-term exposure to high concentrations of $\mathrm{SO}_{2}$ in ambient air is associated with cough and bronchitis in children and that it does not primarily affect the prevalence of BHR and asthma [1, 3, 8, 28-31].

The findings in 5-7 yr olds are also of particular interest for another reason. The prevalence of atopic sensitization and hay fever in 9-11 year olds in Leipzig had increased between 1991/1992 and 1995/1996, while the prevalence of asthma and BHR did not change [14]. This might suggest that factors operating early in life may be particularly important for the development of childhood asthma, whereas the incidence of atopic sensitization and hay fever may also be affected by environmental exposures occurring after infancy. Most of the 5-7 yr old children studied in Dresden and Leipzig in 1995/1996, were born in 1989 or later, and may in part have been exposed to changing living conditions already during the first year of life. However, the prevalence rates of symptoms and diagnoses of asthma in this age group were still lower in Dresden and Leipzig than in Munich. This may indicate that the changes in living conditions of these children occurred too slowly to affect the asthma prevalence. Alternatively, other protective factors may have been effective in the eastern study areas.

It is the objective of this large epidemiological project to investigate potential determinants of the differences in the prevalence of asthma and allergies between children in Dresden, Leipzig and Munich. In this paper the authors report the methods and prevalence rates in children of two age groups in the three study areas. The use of the International Study of Asthma and Allergies in Childhood Phase II protocol will allow the findings to be put into an international perspective. Data on present and previous living and exposure conditions of the study subjects have 

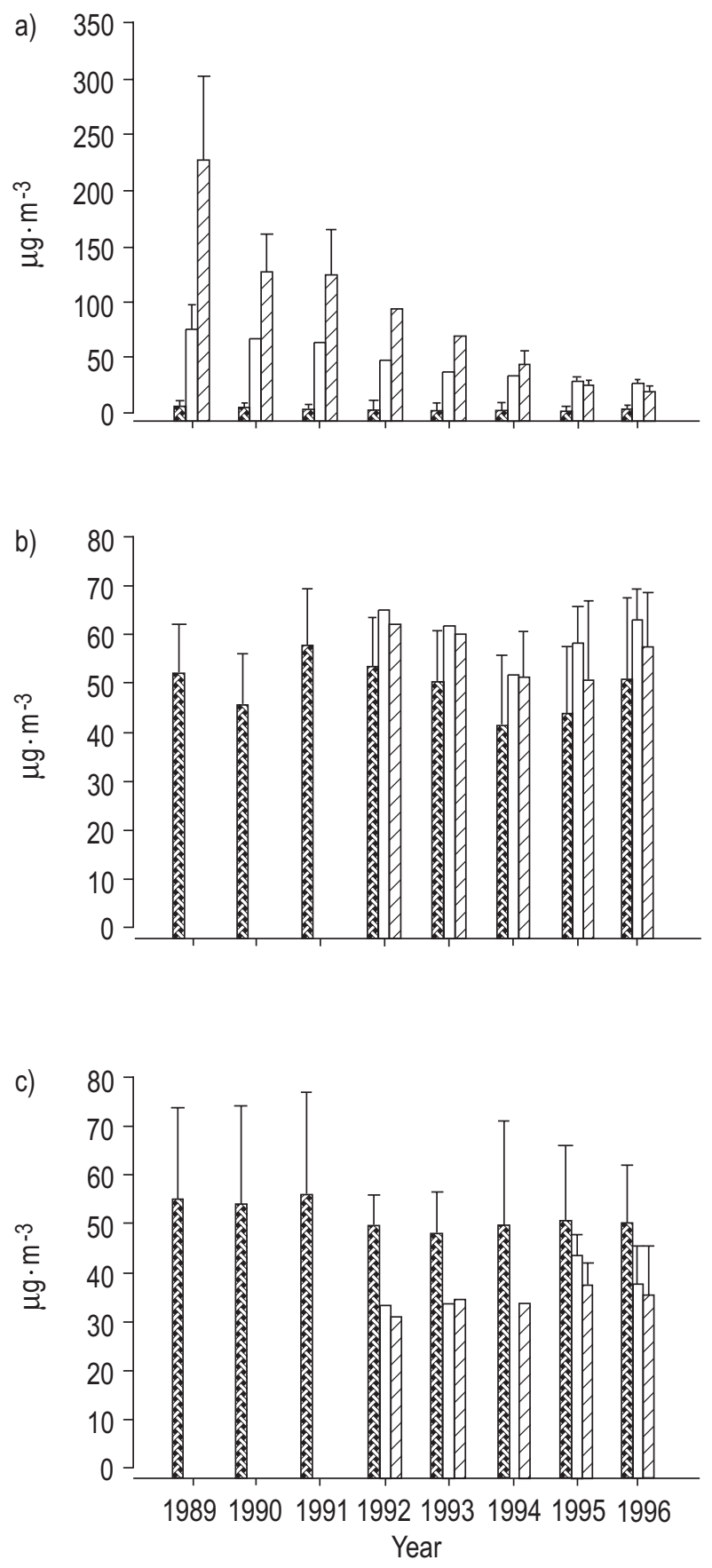

Fig. 1. - Annual concentrations of outdoor air pollution from a) $\mathrm{SO}_{2}$ (ultraviolet fluorescence), b) suspended particulates (SP) (b-absorption) and c) $\mathrm{NO}_{2}$ (chemiluminescence). The mean of all stations (bar) and the station with the highest mean (whisker) are presented. The measurements of $\mathrm{SO}_{2}$ for 1989, 1990 and 1991 in Dresden and Leipzig were performed using a different (coulombmetric) method. : Munich; $\square$ : Dresden; $\mathbb{Z}$ : Leipzig.

been collected by parental questionnaires and, in a nested case-control study on asthma, by parental interviews and measurements of indoor allergens and air pollutants. These data will provide the basis for further aetiological analyses which will be the subject of future reports.

Acknowledgements. The authors thank the pupils, their parents, the heads, teachers, and secretaries of the schools for their help and cooperation during the data collection phase. The authors are also very grateful to P. Gebert from the Gesundheitsarnt der Stadt Dresden, C.B. Spading-Gutsmuths and F.J. Gutsmuths from the Gesundheitsamt der Stadt Leipzig, and Mayer and $H$. Schulte-Sasse from the Gesundheitsamt der Stadt Munich for their help and support. The authors also wish to thank the many field workers for their enthusiasm and dedication, particularly M. Mrach, B. Port, D. Hirsch, and B. Hederer. In addition, we are grateful to Bernhard Schwertner Feldorganisation, Augsburg, who played a major role in the organization of field work, for the excellent collaboration.

\section{References}

1. von Mutius E, Fritzsch C, Weiland SK, Roll G, Magnussen $\mathrm{H}$. Prevalence of asthma and allergic disorders among children in united Germany: a descriptive comparison. BMJ 1992; 305: 1395-1399.

2. Krämer U, Altus $\mathrm{C}$, Behrendt $\mathrm{H}$, et al. Epidemiologische Untersuchungen zur Auswirkung der Luftverschmutzung auf die Gesundheit von Schulanfängern. Forum Städte Hygiene 1992; 43: 82-87.

3. Behrendt H, Krämer U, Dolgner R, et al. Elevated levels of total serum IgE in East German children: atopy, parasites or pollutants? Allergo $J$ 1993; 2: 31-40.

4. von Mutius E, Martinez FD, Fritzsch C, Nicolai T, Roell G, Thiemann HH. Prevalence of asthma and atopy in two areas of West and East Germany. Am J Respir Crit Care Med 1994; 149: 358-364.

5. Braback L, Breborowicz A, Dreborg S, Knutsson A, Pieklik H, Bjorksten B. Atopic sensitization and respiratory symptoms among Polish and Swedish school children. Clin Exp Allergy 1994; 24: 826-835.

6. Braback L, Breborowicz A, Julge K, et al. Risk factors for respiratory symptoms and atopic sensitisation in the Baltic area. Arch Dis Child 1995; 72: 487-493.

7. Jogi R, Janson C, Bjornsson E, Boman G, Bjorksten B. The prevalence of asthmatic respiratory symptoms among adults in Estonian and Swedish university cities. Allergy 1996; 51: 331-336.

8. Nowak D, Heinrich J, Jorres R, et al. Prevalence of respiratory symptoms, bronchial hyperresponsiveness and atopy among adults: west and east Germany. Eur Respir $J$ 1996; 9: 2541-2552.

9. Duhme H, Weiland SK, Rudolph P, Wienke A, Kramer A, Keil U. Asthma and allergies among children in West and East Germany: a comparison between Münster and Greifswald using the ISAAC phase I protocol. Eur Respir $J$ 1998; 11: 840-847.

10. Nicolai T, Bellach B, von Mutius E, Thefeld W, Hoffmeister $\mathrm{H}$. Increased prevalence of sensitization against aeroallergens in adults in West compared with East Germany. Clin Exp Allergy 1997; 27: 886-892.

11. Bjorksten B, Dumitrascu D, Foucard T, et al. Prevalence of childhood asthma, rhinitis and eczema in Scandinavia and Eastern Europe. Eur Respir J 1998; 12: 432-437.

12. Heinrich J, Nowak D, Wassmer G, et al. Age-dependent differences in the prevalence of allergic rhinitis and atopic sensitization between an eastern and a western German city. Allergy 1998; 53: 89-93.

13. von Mutius E, Martinez FD, Fritzsch C, Nicolai T, Reitmeir P, Thiemann HH. Skin test reactivity and number of siblings. BMJ 1994; 308: 692-695. 
14. von Mutius E, Weiland SK, Fritzsch C, Duhme H, Kell U. Increasing prevalence of hay fever and atopy among children in Leipzig, East Germany. Lancet 1998; 351: 862866.

15. Wichmann HE. Possible explanation for the different trends of asthma and allergy in East and West Germany. Clin Exp Allergy 1996; 26: 621-623.

16. Asher MI, Keil U, Anderson HR, et al. Intemational Study of Asthma and Allergies-ISAAC: rationale and methods. Eur Respir J 1995; 8: 483-491.

17. The International Study of Asthma and Allergies in Childhood (ISAAC) Steering Committee. Worldwide variation in prevalence of symptoms of asthma, allergic rhinoconjunctivitis and atopic eczema: The International Study of Asthma and Allergies in Childhood (ISAAC). Lancet 1998; 351: 1225-1232.

18. ISAAC Steering Committee. Phase II Modules of the International Study of Asthma and Allergies in Childhood (ISAAC). Münster, 1998.

19. Weiland SK, von Mutius E, Keil U, für das ISAAC Steering Committee. Die International Study of Asthma and Allergies in Childhood (ISAAC): Forschungsstrategie, Methoden und Ausblick. Allergologie 1999; 5: 275-282.

20. Williams HC, Burney PGJ, Strachan D, Hay RJ. The UK Working Party's diagnostic criteria for atopic dermatitis. II. Observer variation of clinical diagnosis and signs of atopic dermatitis. Br J Dermatol 1994; 131: 397-405.

21. Gardner RM, Hankinson JL, Clausen JL, Crapo RO, Johnson RL, Epler GR. Standardization of spirometry: 1987 update. Official statement of the American Thoracic Society. Am Rev Respir Dis 1987; 136: 1285-1298.

22. Zapletal A, Paul F, Samatiek M. Die Bedeutung heutiger Methoden der Lungenfunktionsdiagnostik zur Fests- tellung einer Obstruktion der Atemwege bei Kindern und Jugendlichen. Z Erkrank Atm Org 1977; 149: 343371.

23. Riedler J, Reade T, Dalton M, Holst D, Robertson C. Hypertonic saline challenge in an epiderniologic survey of asthma in children. Am J Respir Crit Care Med 1994; 150: 1632-1639.

24. Kabesch M, Schaal W, Nicolai T, von Mutius E. Lower prevalence of asthma and atopy in Turkish children living in Germany. Eur Respir J 1999; 13: 577-582.

25. Dold S, Heinrich J, Wichmann HE, Wjst M. Ascaris-specific IgE and allergic sensitization in a cohort of school children in the former East Germany. $J$ Allergy Clin Immunol 1998; 102: 414-420.

26. Burney P, Malmberg E, Chinn S, Jarvis D, Luczynska C, Lai E. The distribution of total and specific serum $\operatorname{IgE}$ in the European Community Respiratory Health Survey. $J$ Allergy Clin Immunol 1997; 99: 314-322.

27. Schafer T, Ring J. Epidemiology of allergic diseases. Allergy 1997; 52 (Suppl. 38): 14-22.

28. Dockery DW, Speizer FE, Stram DO, Ware TH, Spengler JD, Ferris BG Jr.. Effects of inhalable particles on respiratory health of children. Am Rev Respir Dis 1989; 139: 587-594.

29. Magnussen H, Jorres R, Nowak D. Effect of air pollution on the prevalence of asthma and allergy: lessons from the German reunification. Thorax 1993; 48: 879-881.

30. Duhme H, Weiland SK, Keil U. Epidemiological analyses of the relationship between environmental pollution and asthma. Toxicol Lett 1998; 102: 307-316.

31. Braun Fahrlander C, Vuille JC, Sennhauser FH, et al. Respiratory health and long-term exposure to air pollutants in Swiss schoolchildren. Am J Respir Crit Care Med 1997; 155: 1042-1049. 